\title{
Labyrinthe
}

32 | 2009 (1)

Le petit théâtre intellectuel

\section{Le Gourou}

\section{Laurent Dubreuil}

\section{(2) OpenEdition}

\section{Journals}

Édition électronique

URL : http://journals.openedition.org/labyrinthe/3986

DOI : 10.4000/labyrinthe.3986

ISSN : 1950-6031

Éditeur

Hermann

Édition imprimée

Date de publication : 19 juin 2009

Pagination : 43-44

ISBN : 978-2-7056-6885-3

\section{Référence électronique}

Laurent Dubreuil, « Le Gourou », Labyrinthe [En ligne], 32 | 2009 (1), mis en ligne le 01 février 2011, consulté le 20 avril 2019. URL : http://journals.openedition.org/labyrinthe/3986 ; DOI : 10.4000/ labyrinthe.3986 


\section{Le petit théâtre intellectuel}

\section{LE GOUROU}

Est-il encore d'actualité? Sur le théâtre, qui se dit aujourd'hui Gourou passe pour plus archaïque que la Pythie, le chic apocalyptique en moins. Gourou, c'est bon pour les sectes terroristes, pour les théoriciens du marketing, ou les ancêtres de nos aïeux (de Socrate à Siddharta, de Confucius à Diogène). L'Expert aurait beau jeu de montrer que le mot d' « intellectuel » s'impose au moment où le disciple et son maître sont exhibés comme de dangereux irresponsables: " Paradoxe! après 1889, les rééditions du Disciple, ce roman de Paul Bourget contre l'influence intégrale des professeurs de vie, sont comme un signe: alors se prépare l'autonomie particulière de notre catégorie intellectuelle telle que la formulera l'Affaire Dreyfus. » L'argument semble imparable.

Il faut dire que la transmission du magistère de génération en génération, que les jours et les nuits en commun dans une grande maison des faubourgs d'Athènes, que l'itinérance partagée, que la quête conjointe d'un savoir et d'une forme d'existence, tout cela ne fait pas très Lumières. Pas très processus de civilisation non plus. Dans le monde moderne, l'exercice du charisme est incompatible avec le véritable enseignement, demandez à Max Weber. Quant à l'inexorable-spécialisation-de-la-connaissance, imaginez un peu ce qu'elle fait du Patriarche totalisant pour qui vont ensemble le discours, l'exigence morale, la manière de nouer la sandale, le désir pour ses pupilles et l'action politique! Puis qui voudrait se prétendre aujourd'hui exemplaire; et qui serait prêt à suivre le Père dans ses errances?

- Et pourtant, à couvert, en miniature, le Gourou est partout.

Le Blogueur est le Micro-gourou de ses abonnés électroniques, professant la fascinante richesse de son existence mi-virtuelle mi-matérielle. Le Porte-parole gouroutise à l'occasion, quand il devient par exemple l'émissaire de la folie solaire (soyez schizos, faites la ligne pas le point, peignez votre monde à la manière de la panthère rose). La Pythie a ses adeptes, qui reprennent avec elle « Je sais. Mais je n'ai pas les preuves. Je sais parce que je suis un intellectuel $\gg$. Le Comique, qui a des vues d'égale valeur sur l'éthologie sexuelle des animaux et les attentats du 11 septembre, se prend pour un « sage indien » et pérore sur la philosophie morale, après deux ou trois références à Leibniz ou Platon. Le Témoin croit dans 
l'unicité de son expérience, elle devrait informer les autres dans tous les aspects de leurs actions. Et même l'Intellectuel super-objectif, oui même l'Expert se prend un jour à nommer la Vérité, qui, assure-t-il, s'entretient avec lui tous les matins de labeur. Le voici qui requiert de ses ouailles une fidélité concédée volontiers, au nom de la Science évidemment.

«Serions-nous alors des gourous cachés, honteux, des Modèles-réduits? demande le Chøur des Intellectuels. Il est vrai que nous songeons parfois encore à ces petits groupes fondés sur l'élection. L'un d'entre nous, certes néo-classique, n'a-t-il pas écrit "si nous devons choisir entre la secte et la République des Lettres, il nous faut choisir la secte"? D'où nos désirs de groupes d'avant-garde, avec un pape au centre; et la retraite dans l'interzone du campus isolé, au haut d'une tour d'ivoire, sur une colline peuplée de disciples en puissance. »-Mais s'il est vécu plus fort, le rêve gourou érode le rôle « intellectuel »: il est trop loin en arrière avec ses allures obscurantistes, et il est trop au-delà parce qu'il occupe toute la vie. « Voulez-vous vraiment en revenir à Pythagore, vous raser la tête et déambuler en toges avec vos amis pour la défense de la mathématique et du régime végétarien? », interroge le Chœur. Difficile en effet d'occulter le ridicule de la situation, de nier le grotesque de tous ces chefs de file dans l'avant-garde, si sérieux, si graves. Oui sans doute, tant qu'il veut rester lui-même, l'« intellectuel » est surtout Professionnel de la profession, et donc juste Gourou d'occasion; pour de faux, pour de rire.

L. D.

\section{Bibliographie, références, lectures}

I. Jean-Marie Bigard, « Le sage indien », vidéo consultable à l'URL: http:// www.youtube.com/watch? $\mathrm{v}=\mathrm{bRbi3}$ waETHU.

II. Paul Bourget, Le Disciple, Paris, Lemerre, 1889.

III. Gilles Deleuze \& Félix Guattari, Rhizome, Paris, Minuit, 1976.

IV. Diogène Laërce, Vitae Philosophorum.

V. Pier Paolo Pasolini, « Cos'è questo golpe? Io so », Corriere della sera, 14 novembre 1974.

VI. Leo Strauss, On Tyranny, New York, Political Science Classics, 1948.

VII. Max Weber, Wissenschaft als Beruf 1917/1919, Tübingen, Mohr, 1994. 